\title{
HEALTH RISK ASSESSMENT RELATED TO HYDROGEN PEROXIDE PRESENCE IN THE WORKPLACE ATMOSPHERE - ANALYTICAL METHODS EVALUATION FOR AN INNOVATIVE MONITORING PROTOCOL
}

\author{
NICOLA MUCCI ${ }^{1}$, STEFANO DUGHERI ${ }^{2}$, ALESSANDRO BONARI ${ }^{3}$, ANDREA FARIOLI $^{4}$, \\ VENERANDO RAPISARDA ${ }^{5}$, GIACOMO GARZARO ${ }^{6}$, GIOVANNI CAPPELLI ${ }^{1}$, and GIULIO ARCANGELI ${ }^{1}$
}

${ }^{1}$ University of Florence, Florence, Italy

Department of Experimental and Clinical Medicine

${ }^{2}$ Careggi University Hospital, Florence, Italy

Occupational Medicine Unit - Industrial Hygiene and Toxicology Laboratory

${ }^{3}$ Careggi University Hospital, Florence, Italy

General Laboratory

${ }^{4}$ University of Bologna, Bologna, Italy

Department of Medical and Surgical Sciences

${ }^{5}$ University of Catania, Catania, Italy

Department of Clinical and Experimental Medicine

${ }^{6}$ University of Turin, Turin, Italy

Department of Public Health Sciences and Pediatrics

\begin{abstract}
Objectives: Hydrogen peroxide (HP) accounts for $15 \%$ of the total global chemical revenue. According to the National Institute of Occupational Safety and Health, the HP concentration immediately dangerous to human life or health is $75 \mathrm{ppm}$. Operators exposed to HP should pay attention when choosing the monitoring technique that should be specific and sensitive enough to discriminate the exposure levels from background concentrations. In order to assess the long- and short-term exposure to HP in disinfection processes, the authors compared 6 industrial hygiene monitoring methods to evaluate their efficiency in measuring airborne HP concentrations. Material and Methods: Airborne HP concentrations were evaluated using an on-fiber triphenylphosphine solid-phase microextraction method, and they were compared with those obtained using a 13-mm Swinnex titanium oxysulfate filter holder and 4 portable direct-reading electrochemical sensors. A survey carried out in wood pulp bleaching, food and beverage disinfection processing, and in a hospital department to reduce the risk of spreading nosocomial infections, was performed during routine operations to access the risk of HP occupational exposure. Results: Through the generation of HP gaseous dynamic atmospheres (0.1-85 ppm), the authors evaluated the consistency of the results obtained using the 6 methods described. The monitoring campaigns showed that the increase in HP could be
\end{abstract}

Received: June 27, 2019. Accepted: October 30, 2019.

Corresponding author: Stefano Dugheri, Careggi University Hospital, Occupational Medicine Unit - Industrial Hygiene and Toxicology Laboratory, Largo Brambilla 3 , 50139 Firenze, Italy (e-mail: stefano.dugheri@unifi.it). 
relatively high (until $67 \mathrm{ppm}$ ) in food and beverage processing. Conclusions: In the authors' opinion, the current 8-h time-weighted average limits of 1 ppm for HP do not reflect the actual risk; a short-term exposure limit would, therefore, provide a much better protection. Int J Occup Med Environ Health. 2020;33(2):137-50

Key words:

environmental monitoring, occupational medicine, hydrogen peroxide, exposure scenario, airborne exposure, electrochemical sensor

\section{INTRODUCTION}

The global market for hydrogen peroxide (HP, CAS No. 7722-84-1) is forecast to reach 5.7 million metric tons by 2022. Asia-Pacific constitutes the largest and fastest growing market worldwide. Hydrogen peroxide accounts for $15 \%$ of the total global chemical revenue [1]. The main use of HP in the world is for bleaching pulp. Other uses include chemicals manufacture and HP as an intermediate in the synthesis of chemicals, in the bleaching of textiles, wastewater and waste gas treatment, disinfection, and beverage packing.

The American Conference of Governmental Industrial Hygienists (ACGIH) has indicated that HP is a confirmed animal carcinogen with unknown relevance to human carcinogenicity. Zienolddiny et al. [2] have found that different dilutions of a $30 \%$ solution of HP, when added to cell culture mediums, display mutagenic effects, producing reactive oxygen species that could result in direct DNA and protein damage. According to the National Institute of Occupational Safety and Health (NIOSH), the HP concentration immediately dangerous to life and health (IDLH) is $75 \mathrm{ppm}$.

Currently, there are substantial differences among the guidelines concerning HP occupational exposure provided by various associations, not only in terms of the parts per million limits but also regarding values to be assessed [3]. For example, Deutsche Forschungsgemeinschaft (DFG) proposes recommended exposure limits as an 8-h time-weighted average (TWA) (0.5 ppm) and a short-term exposure limit (STEL) (0.5 ppm), which are significantly lower than the workplace exposure limits indicated by Finland's health and safety executives (1 ppm for TWA and 3 ppm for 15-min STEL). In contrast, the Occupational Safety and Health Administration
(OSHA), NIOSH and ACGIH have established a permissible exposure limit, a recommended exposure limit and a threshold limit value of $1.0 \mathrm{ppm}$, calculated as an 8-h TWA, and do not indicate HP occupational exposure limits in terms of STEL. The European Union (EU) has proposed an adverse effect level for inhalation exposure equal to 0.9 ppm for acute, medium- and long-term exposure, based on the no-adverse-effect level being observed in a 90-day inhalation rat study [4]. The EU Regulation concerning the Registration, Evaluation, Authorisation and Restriction of Chemicals (REACH) has set the values of the derived no-effect level (DNEL) for HP at $1.4 \mathrm{mg} / \mathrm{m}^{3}$ and $3 \mathrm{mg} / \mathrm{m}^{3}$ for long-term and acute shortterm exposures, respectively [5].

To date, there have been few proposed analytical methods applied in the field of industrial hygiene. These involve the sampling method using titanium tetrachloride, potassium dioxalatooxotitanat(IV), titanium oxysulfate hydrate $\left(\mathrm{TiOSO}_{4}\right)$, and triphenylphosphine (TPP) [6-12] as reagents, whether on filters or impingers, followed by colorimetric spectroscopy, pulse polarography or liquid chromatography. Other analytical methods suitable for determining airborne HP concentrations have been proposed in the environmental field, including UV photolysis [13], chemiluminescence [14,15], Fourier transform infrared spectroscopy (FTIR) [16], tunable diode laser absorption spectrometry (TDLAS) [17], and fluorescence spectrometry, with and without chromatographic separation [12,18-20]. Unfortunately, the latter 6 methods require trained operators and rather expensive and complex equipment, in order to be used for analytical purposes, even though they are characterized by low detection limits. In this scenario, the direct determination of HP concentrations for industri- 
al hygiene measurements, without preconcentration steps, appears to be remarkable. There is a significant demand for compact instruments that can provide real-time exposure data on-site and require minimum time for preparation and maintenance. Electrochemical sensors for airborne HP detection are small and convenient real-time portable instruments which have recently enjoyed much interest from various authors [21,22]. In 2015, the total opportunity cost for HP measurement devices was USD $28 \mathrm{mln}$ in Europe, projected to expand at a compound annual growth rate (CAGR) of 6.0\% in 2016-2024. By the end of 2024, it is likely to reach USD $42.7 \mathrm{mln}$ [23].

The aim of this work is to assess the long- and short-term exposure to airborne HP by comparing 6 analytical methods. This paper describes the evaluation and validation protocol used for assessing the HP occupational exposure levels in food and beverage processing, wood pulp bleaching, and hospital high-level disinfection, during high-risk operations, in line with the exposure scenarios reported in literature [4]. Thus, a new solid-phase microextraction (SPME)/ fast gas chromatography (GC)-mass spectrometry (MS) HP detection method has been developed and compared with 4 electrochemical sensors and a modified $\mathrm{TiOSO}_{4}$ spectrophotometric monitoring to detect overexposure to HP.

\section{MATERIAL AND METHODS}

\section{Measurement devices}

For the diffusive analytical technique, a Fast Fit Fiber Assemblies (FFA)-SPME $30 \mu \mathrm{m}$ polydimethylsiloxane fiber (Cat. No. FFA57289-U, Supelco, Bellefonte, USA) was doped for $120 \mathrm{~s}$ in the headspace of a $10 \mathrm{ml}$ vial, preheated at $90^{\circ} \mathrm{C}$ for $20 \mathrm{~min}$ and containing $100 \mathrm{mg}$ of TPP (CAS No. 603-35-0, Cat. No. T84409, Sigma-Aldrich, Saint Louis, USA). From the reaction between HP and TPP, triphenylphosphine oxide (TPPO, CAS No. 791-28-6, Cat. No. T84603, SigmaAldrich, Saint Louis, USA) was obtained [24,25]. Personal sampling was performed by rapid FFA-SPME [26] (60 s) and by TWA-FFA-SPME [27] ( $8 \mathrm{~h}$ ) through a diffusive sam- pling fiber holder (Supelco, Bellefonte, USA). After sampling, HP was analyzed with fast GC/MS with a Shimadzu GC 2010-MS QP 2010 series (Shimadzu, Kyoto, Japan), operating in the electron ionization (EI) mode, full-scan, using the base peak from the $70 \mathrm{eV}$ EI spectra as the quantitation ion, as follows: TPP (retention time, RT, $4.04 \mathrm{~min}$ ), m/z 262 and TPPO (RT $4.67 \mathrm{~min}$ ), $\mathrm{m} / \mathrm{z} 277$. The initial oven column temperature for the MEGA-5 MS column $(10 \mathrm{~m} \times 0.10 \mathrm{~mm}$ $\times 0.1 \mu \mathrm{m}$ film thickness, MEGA, Legnano, Italy) was set to $70^{\circ} \mathrm{C}$ for $0.3 \mathrm{~min}$, and then increased at $50^{\circ} \mathrm{C} / \mathrm{min}$ to $300^{\circ} \mathrm{C}$ (total run time: $4.90 \mathrm{~min}$ ). Helium $(99.999 \%)$ at a flow rate of $1.10 \mathrm{ml} / \mathrm{min}$ was used as carrier gas. For desorbing the analytes, the SPME fiber was introduced into the GC injector port and maintained at $280^{\circ} \mathrm{C}$ for $2 \mathrm{~min}$. Full automation of the procedure was achieved using a new Flex GC autosampler (EST Analytical, Fairfield, USA), equipped with a 45-position Multi Fiber Exchange. The cross reactivity to peracetic acid was avoided through an assembled cassette with a quartz filter impregnated with an ethanol/ water 2,2'-azino-bis(3-ethyl-benzothiazoline)-6-sulfonate (ABTS, CAS No. 30931-67-0, Cat. No. 10102946001, Sigma-Aldrich, Saint Louis, USA) solution [28] and connected to FFA-SPME [26].

For active sampling, the method proposed by Hecht et al. [6] was used with some modifications. An air flow ranging $0.1-1.0 \mathrm{l} / \mathrm{min}$ was applied to a mini-sampler openface $13 \mathrm{~mm}$ Swinnex holder (Cat. No. 225-6201, Eighty Four, SKC) assembled on a 13-mm quartz filter (Cat. No. A080A013A, Advantec MFS, Inc., Dublin, CA, USA) previously soaked with $100 \mu \mathrm{l}$ of $50 \mathrm{mg} / \mathrm{ml} 0.9 \mathrm{M} \mathrm{H}_{2} \mathrm{SO}_{4}$ $\mathrm{TiOSO}_{4}$ (CAS No. 123334-00-9, Cat. No. 463914, SigmaAldrich, Saint Louis, USA), and then dried for $1 \mathrm{~h}$ in an oven at $60^{\circ} \mathrm{C}$. Moreover, to enable the positioning of the sampler inlets within the proximity of the operator's nose and mouth, the authors used a face-level sampling headset (Cat. No. 225-6200, SKC, Eighty Four, USA). The GilAir Plus personal sampling pumps were supplied by Sensydine (St. Petersburg, USA). After sampling, 
Table 1. The technical data of the direct reading of electrochemical instruments and GC/MS laboratory analytical methods in the study on hydrogen peroxide monitoring

\begin{tabular}{llccc}
\hline \multicolumn{1}{c}{ Instrument } & Sampling mode & $\begin{array}{c}\text { Measuring range } \\
{[\mathrm{ppm}]}\end{array}$ & $\begin{array}{c}\text { Resolution } \\
{[\mathrm{ppm}]}\end{array}$ & Detection system \\
\hline $\begin{array}{l}\text { ATI Series C16 PortaSens II (Analytical } \\
\text { Technology Inc, Collegeville, USA) }\end{array}$ & active & $0-200$ & 0.1 & electrochemical \\
$\begin{array}{c}\text { Interscan 4000 Series Compact (Interscan } \\
\text { Corporation, Simi Valley, USA) }\end{array}$ & active & $0-199.9$ & 0.1 & $\begin{array}{c}\text { electrochemical } \\
\text { voltammetric sensor } \\
\text { electrochemical }\end{array}$ \\
$\begin{array}{l}\text { SafeCide portable monitoring system } \\
\quad \text { ChemDAQ, Pittsburgh, USA) }\end{array}$ & passive & $0-20$ & 0.1 & electrochemical \\
$\begin{array}{l}\text { Dräger X-am 5100 (Drägerwerk AG \& Co. } \\
\quad \text { KgaA, Lübeck, Germany) }\end{array}$ & passive & $0-20$ & 0.1 & mass spectrometry \\
$\begin{array}{l}\text { Swinnex titanium oxysulfate filter } \\
\quad \text { SKC Inc., Palo Alto, USA) }\end{array}$ & active & 0.04 & 0.01 & mass spectrometry \\
$\begin{array}{l}\text { TPP PDMS SPME-fiber (Merck KGaA, } \\
\text { Darmstadt, Germany) }\end{array}$ & passive/diffusive & 0.03 & 0.01 & \\
\hline
\end{tabular}

the concentration of the complex led to the formation of a yellow product with the highest absorbance observed at $410 \mathrm{~nm}$, which was then evaluated on-site using a DR 1900 portable spectrophotometer (Hach Company, Loveland, USA) previous elution with $2 \mathrm{ml}$ of $\mathrm{H}_{2} \mathrm{SO}_{4} 1 \mathrm{M}$.

Air monitoring by a portable continuous direct reading detector was evaluated using:

- the ATI Series C16 PortaSens II portable gas leak detector (Analytical Technology Inc, Collegeville, USA);

- the Interscan 4000 Series Compact portable analyzer (Interscan Corporation, Simi Valley, USA);

- the SafeCide portable monitoring system (ChemDAQ, Pittsburgh, USA);

- the Dräger X-am 5100 gas detection meter (Drägerwerk AG \& Co. KgaA, Lübeck, Germany).

The technical data of the 4 portable instruments are shown in Table 1.

\section{Dynamic calibration system}

In order to obtain air samples containing known concentrations of HP, the authors made use of the dynamic system proposed in previous works [29-31] with some modifications. The Harvard Plus 11 syringe pump (Harvard Appara- tus, Holliston, USA), equipped with a $1 \mathrm{ml}$ gas-tight syringe set to $2 \mu \mathrm{l} / \mathrm{min}$, connected to the Adsorbent Tube Injector System (ATIS) (Supelco, Bellefonte, USA), was used to generate HP vapor. All 6 samplers were simultaneously exposed to each HP air concentration, and for each one, 5 determinations were performed. The HP air concentration $\left(\mathrm{C}_{\mathrm{HP} \text { air }}\right)$ was calculated using the following formula:

$$
\mathrm{C}_{\mathrm{HP} \mathrm{air}}=\mathrm{C}_{\mathrm{Sol}} \mathrm{F}_{\text {syringe }} / \mathrm{F}_{\text {air }}
$$

where:

$\mathrm{C}_{\mathrm{HP} \text { air }}$ - the concentration of the analyte in the air $(\mathrm{mg} / \mathrm{l})$,

$\mathrm{C}_{\mathrm{Sol}}$ - the concentration of the solution $(\mathrm{mg} / \mathrm{ml})$,

$\mathrm{F}_{\text {syringe }}$ - the syringe pump flow ( $\left.\mathrm{ml} / \mathrm{min}\right)$,

$\mathrm{F}_{\text {air }}$ - the air flow (1/min).

The concentration of the water vapor produced by the impinger was determined by measuring the dew point temperature with the photoacoustic infrared Innova type 1312 multigas monitor (LumaSense Technologies, Milpitas, USA). Atmospheric pressure was determined with the GE Druck DPI 705 digital pressure indicator (General Electric, Boston, USA). 


\section{Statistical analysis}

In Table 2, the authors reported the theoretical HP atmospheric concentrations tested, and the relative observed mean and standard deviation measurements for each method. The statistical analysis was conducted using Stata software release 11 (StataCorp LP). Simple regression models were performed to assess calibration between the theoretical and measured values, and the authors evaluated the hypothesis of "perfect calibration" ( $\mathrm{H} 0: \beta=1, \alpha=0)$. They thus reported estimates of $\alpha$ and $\beta$ with the standard error (SE) and the p-value, performing a hypothesis test with F statistics involving coefficient restriction. Finally, the $r^{2}$ value was calculated to verify the goodness of fit of the estimated regression model for each method.

\section{Sampling sites}

A survey carried out in wood pulp bleaching - estimated to hold the largest share of the industrial HP market food and beverage disinfection processing, and a hospital department to reduce the risk of spreading nosocomial infections, was performed during routine operations to access the risk of HP occupational exposure. Measurements of HP vapor were performed in the following industrial segments:

- pulp and paper manufacturing, during HP tank refilling,

- soft drinks manufacturing during servicing of a highspeed filling machine,

- hospital intensive care units after HP nebulization.

The BABUC/A multi-data logger (LSI Lastem, Milano, Italy) was employed to measure temperature, relative humidity and air velocity during air sampling.

\section{RESULTS}

\section{Performance of the 6 methods}

The analytical procedure combines the efficiency of fast GC/MS systems with both high automation throughput and the quantitative accuracy of SPME on-fiber derivatization.
This method allows for automated assays to be performed in very short time windows, characterized by higher sensitivity power (the theoretical and experimental sampling rate values [SRs] were $0.0397 \mathrm{ml} / \mathrm{min}$ and $0.0324 \mathrm{ml} / \mathrm{min}$, respectively) and discrimination than other routine techniques employed in hygiene industrial laboratories, thanks to the structurally informative MS fragmentation pattern (Figure 1).

Calibration curves, simple regression parameters, and the limit of detection(LOD)/limit of quantification (LOQ) values were reported in Table 2. In particular, the TPPPDMS-TWA-SPME fiber showed the lowest LOQ value $(0.009 \mathrm{ppm})$ and the best goodness of fit $\left(\mathrm{r}^{2}=0.999\right)$ of the calibration with theoretical HP atmospheric concentrations. Given the level of significance expressed as a p-value of 0.05 , the authors did not obtain any evidence to reject the null hypothesis $\left(\mathrm{H}_{0}\right)$ for all the 5 methods under evaluation.

\section{Monitoring campaigns}

The monitoring campaigns showed that the increase in HP could be relatively high: in particular, a HP concentration of up to $67 \mathrm{ppm}$ was measured in food and beverage processing. The exposure scenarios presented in Table 3 are in line with the inference method [29] that may be applied to a substance with a full-shift limit value when the integrated air sampling is significantly lower than TWA and the STEL level has not been set. This consideration is especially important for HP because of its lack of biological monitoring and odor. As many as $6 \%$ of all measurements performed during bottle outfeed in food and beverage plants provided results close to the IDLH value.

\section{DISCUSSION}

This paper aims to support the development of HP workrelated exposure limits by means of evaluation of human exposure in several key occupational settings. The authors suggest that occupational medicine could be a precious 


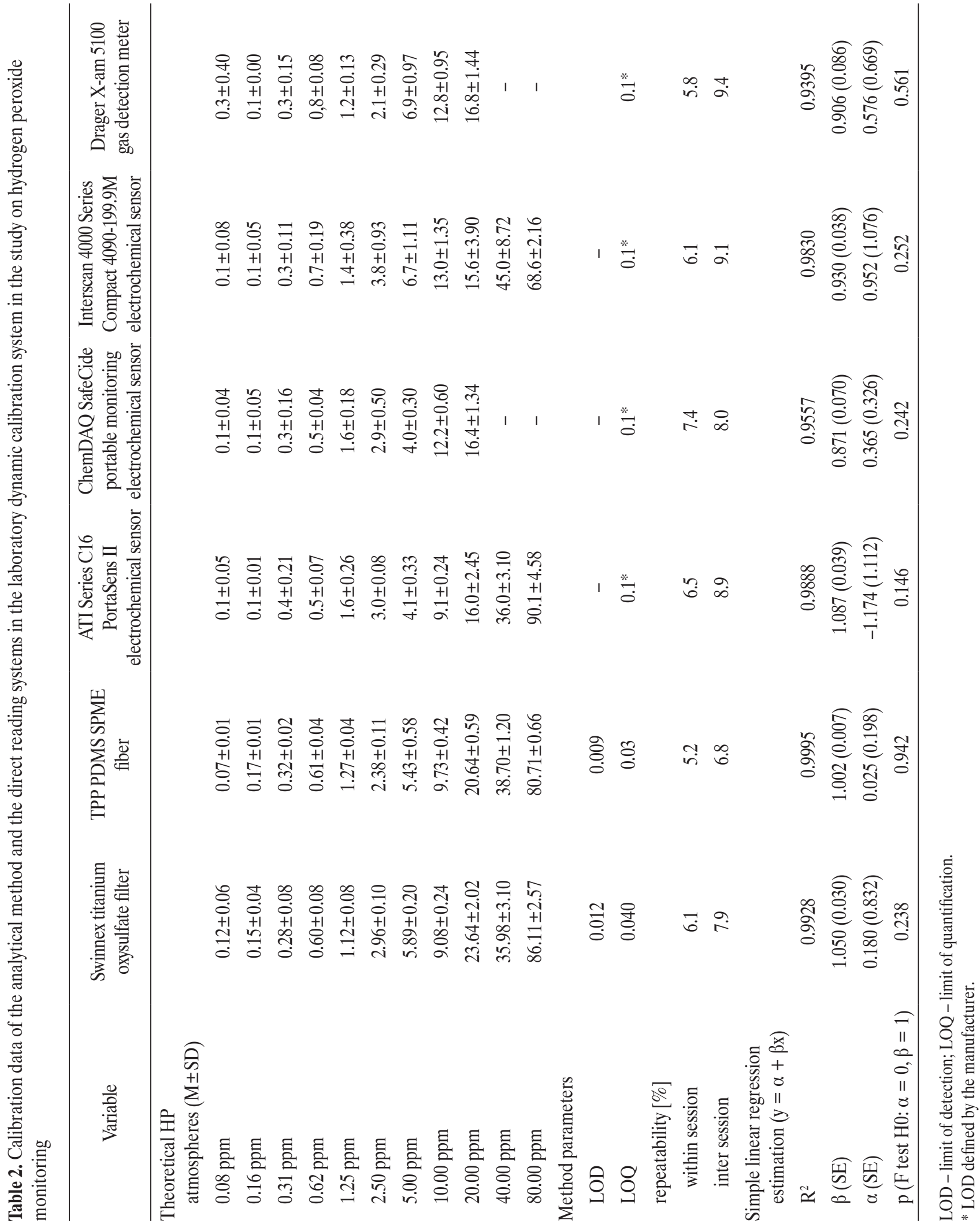




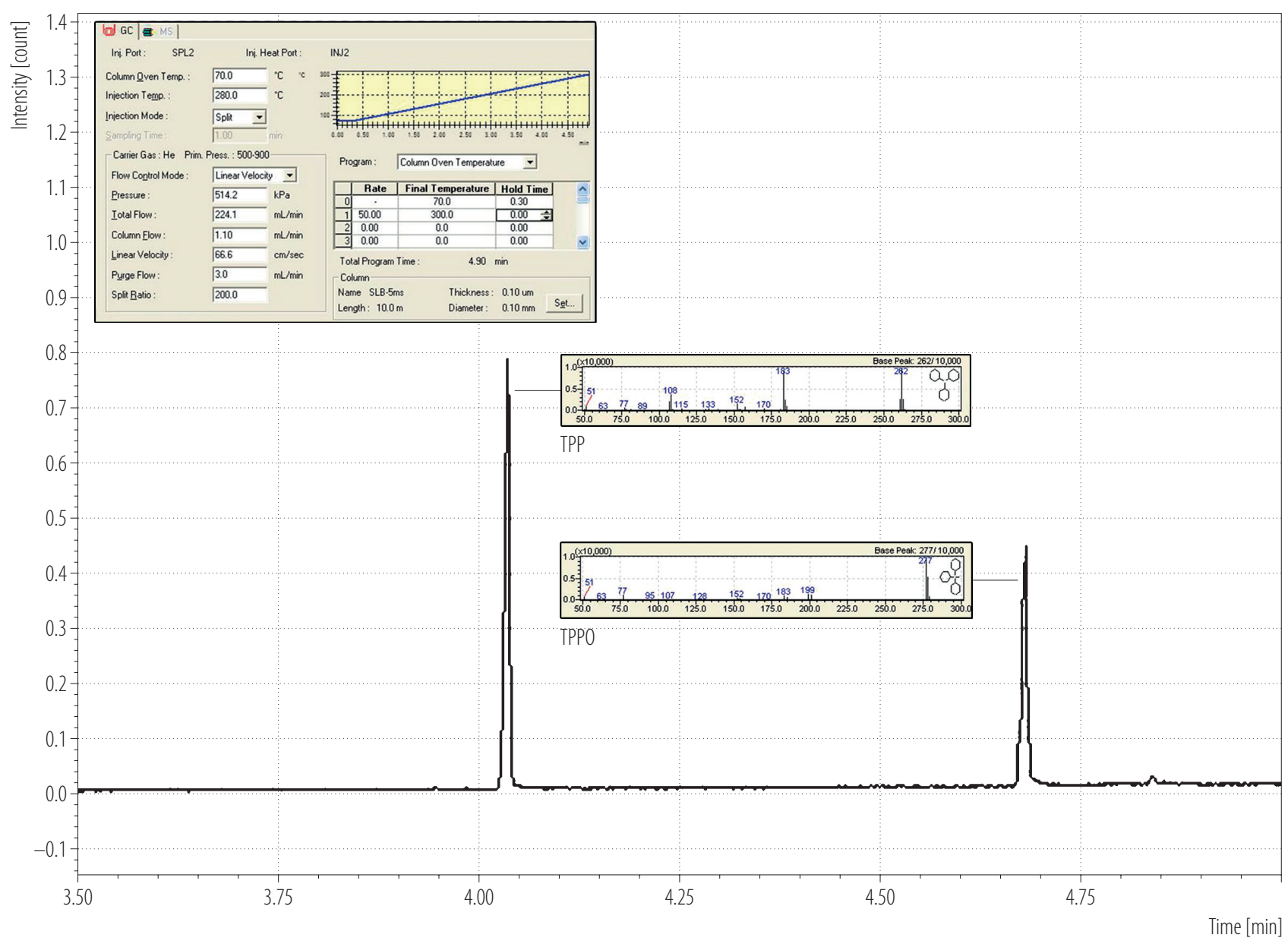

Figure 1. Gas chromatography conditions, chromatogram and fragmentation patterns of the triphenylphosphine (TPP) and triphenylphosphine oxide (TPPO) analysis in the study on hydrogen peroxide monitoring

contributor to the growth of exposure science, including also the problem of environmental contamination, thanks to the methods and knowledge derived from the investigations performed by the authors [32-35].

There is a growing use of HP as a sterilizing agent in industrial applications but its toxicity is often underestimated [36]. It tends to be overused, as a result of which significant amounts of HP frequently remain in the workplace atmosphere.

Data on the acute and chronic toxicity of HP are limited and outdated. Respiratory irritation symptoms have been reported among manufacturing plant workers exposed to HP. A single case of a long-term inhalation exposure with dyspnea and bilateral diffuse nodular infiltrates on the lung has also been seen [37]. A survey of the health surveillance data on the production workers encompassed 110 workers, of whom 80 had been involved in the production for $>10$ years. The mean levels of HP revealed were $<1 \mathrm{ppm}$ whereas short-term concentrations were up to about $3.5 \mathrm{ppm}$, and about $7 \mathrm{ppm}$ in accidental situations [38]. The Finnish Institute of Occupational Health conducted a study inside a company, focusing on a small group of workers exposed to HP vapor; peak exposures of up to 8 ppm (8-h TWA 2 ppm) of HP in the air were measured in the breathing zone of the individuals [39]. In line with the exposure assessment scenario specified in 


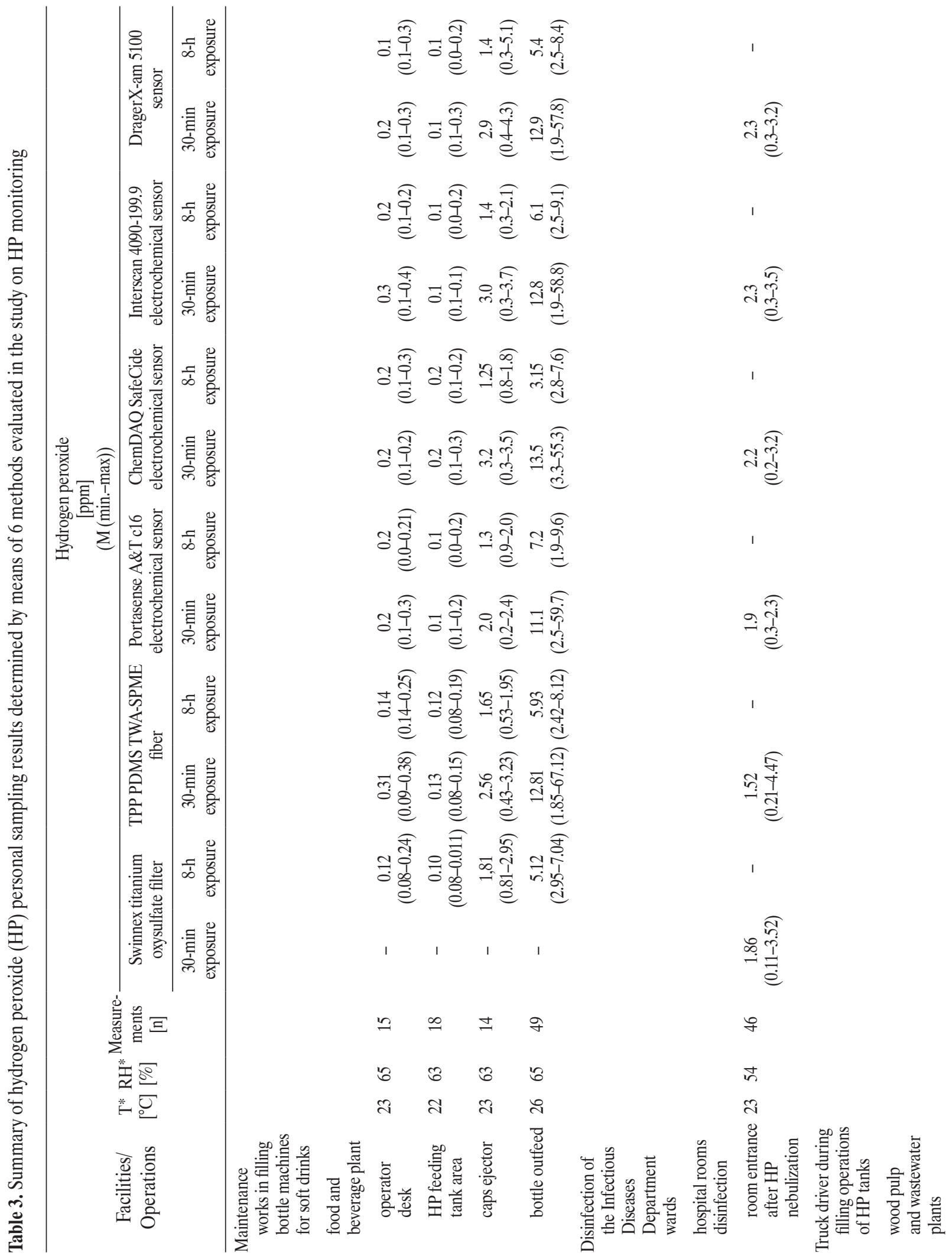




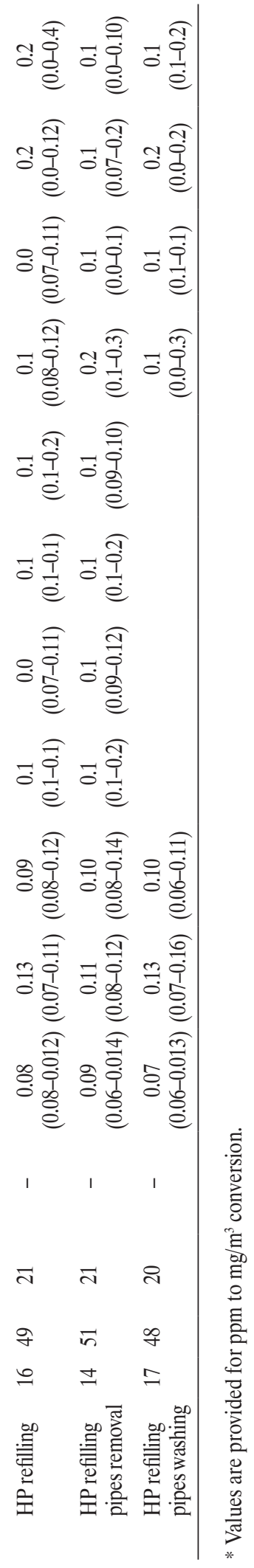

EU Regulation No. 528/2012 [5], the field data presented by the authors of this paper show the possibility of having occupational exposure values even close to the IDLH. In their opinion, the current 8-h TWA limits for HP do not reflect the actual risk; STEL would, therefore, provide a much better protection.

Since there are few conventional methods of assessing HP exposure in the field of industrial hygiene, the authors decided to expand their considerations to methods for the determination of airborne HP environmental concentrations. These methods are almost always time-consuming since they require preconcentration, before the proper analysis, of the atmosphere to be analyzed in a suitable trapping solution, by resorting to appropriate solid or liquid-phase scrubbers, or to stripping coils or denuders. As regard the use of impingers, this method has several disadvantages, i.e., it is not particularly suited to personal sampling and its use often leads to the production of artifacts, which are bound to liquid phase production and decomposition [40,41]. Using the denuder as a sampling trap requires a coating procedure and extraction of the collected gases. Both these procedures are labor-intensive and require trained operators [42].

The analytical methods employed by the authors are fully automated and allow data management, from the indirect and direct reading methods through to dedicated software. All 6 samplers were employed remotely by the HP Data Storing System (Chromline, Prato, Italy) as much as possible to avoid operator variability or mistakes. The sampling data and their analytical results were then integrated into a laboratory information management system (LIMS, Bika Lab System, South Africa) which generates reports and analyzes historical data (Figure 2). Combining the rapid FFA-SPME 1-min device and the electrochemical instrument enabled the authors to identify the moments when peaks occurred throughout emissions. Specifically, comparing the repeated continuous monitoring data with the long- and short-term limit values 


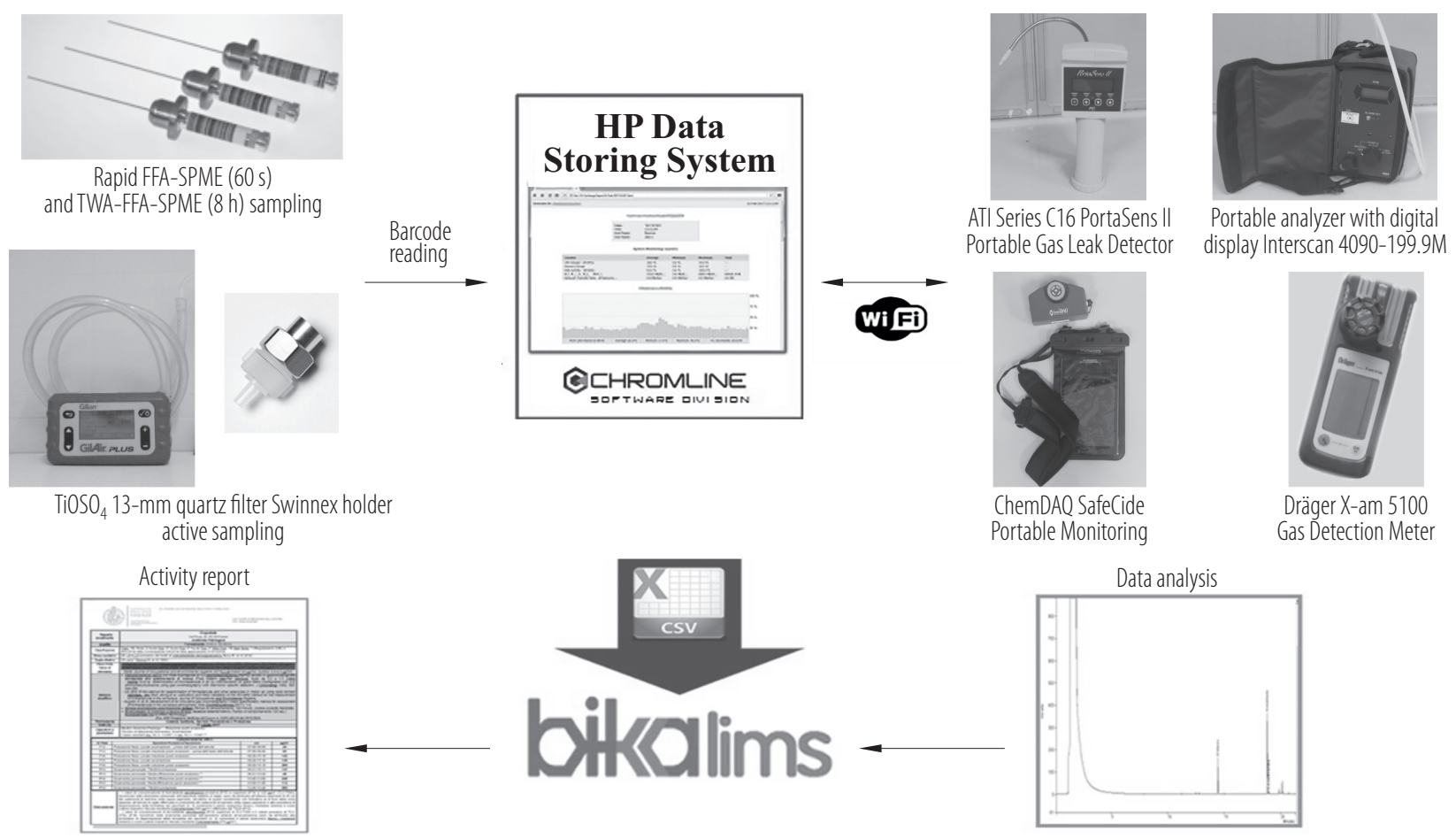

Figure 2. Laboratory information management system in the study on hydrogen peroxide monitoring

gave a picture of workplace exposure. On the downside, the rapid FFA-SPME requires a large number of fibers for sampling while the electrochemical sensors may have low specificity in certain conditions, but the SPME makes up for these shortcomings. The TWA limit values could be evaluated easily in terms of feasibility for operators by $\mathrm{TiOSO}_{4}$ 13-mm quartz filter Swinnex holder active sampling and TWA-FFA-SPME, which are both validated analytical methods.

Several approaches could be useful to test the calibration of methods from airborne compounds. The Bland-Altman plot [43] is usually adopted in clinical chemistry, and it is capable of assessing the consistency between 2 measurement techniques. The differences (or, alternatively, the ratios) between 2 techniques are plotted against their average values. Alternatively, the differences can be plotted against 1 of the 2 methods, if this method is considered a reference or "golden standard" method [44]. Otherwise, the concordance of measurements performed with different analytical methods is commonly compared pairwise using Pearson's test, evaluating the linear correlation between 2 variables [30,45,46]. Passing and Bablok [47] have described a linear regression procedure with no special assumptions regarding the distribution of the samples and measurement errors. The results do not depend on the assignment of the methods to $\mathrm{X}$ and $\mathrm{Y}$. The slope and intercept are computed with their $95 \%$ confidence intervals (CIs). These CIs are then used to determine whether there is only a chance difference between the slope and 1 , and between the intercept values and 0 .

Herein, the authors have proposed a different hypothesis test with F statistics to compare the concordance between theoretical calibration atmospheres and measured values using different systems. The restriction of the $\alpha$ and $\beta$ coefficients makes it possible to analyze the regression model in order to infer the compliance with the idea of 
"perfect calibration" ( $\alpha=0$ and $\beta=1)$. According to the authors, this approach gives the advantage to evaluate the calibration of validated laboratory methods and direct reading instruments together, testing in the same condition of the measurements performed in the workplaces.

\section{CONCLUSIONS}

The aim of this work was to create an innovative monitoring approach measuring airborne HP concentrations in the workplace, which would be simple, fast and sensitive. To this end, 2 laboratory-based methods were evaluated with 4 commercially available direct-reading instruments, yielding comparable results. Unlike the TPP passive method which involves thermal desorption, the $\mathrm{TiOSO}_{4}$ active sampling method requires chemical extraction before detection into a spectrophotometric unit. This problem is easily overcome by using SPME, a solventfree technique that incorporates sampling, isolation and enrichment in 1 step. The derivatization kinetics showed that the reaction of TPP with HP was instantaneous during the sampling, and the SPME fiber retraction inside the needle allowed an excellent evaluation of TWA-occupational exposure limits. A database management system provided a central database that could be accessed by multiple users in a controlled manner. Its interface with Bika LIMS allowed for certain instruments, quality control, and ISO 17025 accreditation to be implemented, thus eliminating human error and reducing the costs of administration.

To conclude, the HP air monitoring protocol provides a remote integration of 6 monitoring systems in order to simplify sampling and analytic operations, setting the future bases for on-site analyses regarding second-level methods. In fact, as the number of different types of portable GC instruments with different complexity and capacity has continued to grow, the chromatographic method proposed is capable of being accepted by this technology. The authors recommend the simultaneous use of both first- and second-level measurement methods; the choice of the instruments/methods to be adopted will be based on various factors, such as the financial resources available, the expected concentration and range values, the operator's experience, and the exposure scenario.

Moreover, due to the circumstances in which the TLVTWA value is exceeded in normal use cases, a protocol to evaluate long- and short-term exposure to HP vapor is needed. The presented data show the possibility of having occupational exposure values even close to the 30 -min IDLH limit. The monitoring campaigns showed that the increase in HP could be until 67 ppm and the 1 ppm current 8-h TWA limits for HP do not reflect the actual risk; STEL would, therefore, provide a much better protection. Exposures above the TLV-TWA values, and up to the TLV-STEL value, should not be longer than $15 \mathrm{~min}$ and should not occur $>4$ times/day, with a minimum interval of $60 \mathrm{~min}$ between exposures in this range.

The experimental and field comparisons showed that the aforementioned HP vapor measuring methods are consistent and can be easily integrated into an industrial hygiene plan to prevent significant acute toxicity resulting from HP vapor. Therefore, this protocol can be seen as constituting a reliable method for determining airborne $\mathrm{HP}$ concentrations in routine analyses.

\section{REFERENCES}

1. Global Industry Analysts Inc. [Internet]. San Jose: Global Industry Analysts Inc; 2019 [cited 2019 Jun 4]. Hydrogen Peroxide - A global strategic business report. Available from: http:/ www.strategyr.com/MarketResearch/infographTemplate. asp? code $=$ MCP -2080 .

2. Zienolddiny S, Ryberg D, Haugen A. Induction of microsatellite mutations by oxidative agents in human lung cancer cell lines. Carcinogenesis. 2000;21:1521-6, https://doi.org/10. 1093/carcin/21.5.521.

3. Institute for Occupational Safety and Health of the German Social Accident Insurance (IFA) - Deutsche Gesetzlich 
Unfallversicherung (DGUV). [Internet]. Sankt Augustin: IFA; 2019 [cited 2019 Jun 4]. GESTIS substance database. Available from: https://www.dguv.de/ifa/gestis/gestis-stoffdatenbank/index-2.jsp.

4. Regulation (EU) No 528/2012 concerning the making available on the market and use of biocidal products. Off J Eur Union 2012;167:1-116.

5. European Chemicals Agency [Internet]. Helsinki: ECHA; 2017 [cited 2019 Jun 10]. Regulation concerning the Registration, Evaluation, Authorisation and Restriction of Chemicals, Hydrogen Peroxyde-Registration Dossier. Available from: https://echa.europa.eu/registration-dossier/-/ registered-dossier/15701/7/1.

6. Hecht G, Héry M, Hubert G, Subra I. Simultaneous sampling of peroxyacetic acid and hydrogen peroxide in workplace atmospheres. Ann Occup Hyg. 2004;48:715-21, https:// doi.org/10.1093/annhyg/meh067.

7. Christensen CS, Brødsgaard S, Mortensen P, Egmose K, Linde SA. Determination of hydrogen peroxide in workplace air: interferences and method validation. J Environ Monit. 2000;2:339-43, https://doi.org/10.1039/b001799j.

8. Schuh C. Peroxides (peracetic acid and hydrogen peroxide). In: The MAK Collection Part III, Air Monitoring Methods. Wiley-VCH Verlag GmbH \& Co. KGaA, editors. Bonn: Deutsche Forschungsgemeinschaft; 2013. p. 1-22.

9. Occupational Safety and Health Administration [Internet]. Salt Lake: OSHA; 2014; [cited 2019 Jun 10]. Hydrogen Peroxide in Workplace Atmospheres. Method no. ID-126SG. Available from: https://www.osha.gov/dts/sltc/methods/ partial/t-id126sg-pv-01-0201-m/t-id126sg-pv-01-0201-m. html.

10. Hecht G, Aubert S, Gerardin F, Hery M. Workplace monitoring of hydrogen peroxide using titanyl-coated sorbents. J Environ Monit. 1999;1:149-52, https://doi.org/10.1039/ a808686i.

11. Breuer D, Adelmann M. Hydrogen peroxide [Air Monitoring Methods, 2003]. In: The MAK-Collection for Occupational Health and Safety: Annual Thresholds and
Classifications for the Workplace. 2002. p. 123-33, https:// doi.org/10.1002/3527600418.am772284e0008.

12. Jacob P, Tavares TM, Klockow D. Methodology for the determination of gaseous hydrogen peroxide in ambient air. Fresenius J Anal Chem. 1986;325(4):359-64, https://doi.org/ 10.1007/BF00505460.

13. Liu J, Steinberg SM, Johnson BJ. A high-performance liquid chromatography method for determination of gas-phase hydrogen peroxide in ambient air using Fenton's chemistry. Elsevier. 2003;52:815-23, https://doi.org/10.1016/S0045-6535 (03)00260-1.

14. Kok GL, Darnall KR, Winer AM, Pitts JN, Gay BW. Ambient Air Measurements of Hydrogen Peroxide in the California South Coast Air Basin. Environ Sci Technol. 1978;12(9):1077-80, https://doi.org/10.1021/es60145a011.

15. Kok GL, Holler TP, Lopez MB, Nachtrleb HA, Yuan M. Chemiluminescent Method for Determination of Hydrogen Peroxide in the Ambient Atmosphere. Environ Sci Technol. 1978;12(9):1072-6, https://doi.org/10.1021/es60145a010.

16. Tuazon EC, Winer AM, Graham RA, Pitts JN. Atmospheric measurements of trace pollutants by kilometer-path lenght FTIR spectroscopy. Adv Environ Sci Technol. 1980;10:259-300. 17. Slemr F, Harris GW, Hastie DR, Mackay GI, Schiff HI. Measurement of gas phase hydrogen peroxide in air by tunable diode laser absorption spectroscopy. J Geophys Res Atmosph. 1986;91(D5):5371-8, https://doi.org/10.1029/JD09 1iD05p05371.

18. Lee JH, Chen Y, Tang IN. Heterogeneous Loss of Gaseous H2O2 in an Atmospheric Air Sampling System. Environ Sci Technol. 1991;25(2):339-42, https://doi.org/10.1021/es00 014a019.

19. Lazrus AL, Kok GL, Lind JA, Gitlin SN, Heikes BG, Shetter RE. Automated Fluorometric Method for Hydrogen Peroxide in Air. Anal Chem. 1986;58(3):594-7, https://doi. org/10.1021/ac00294a024.

20. Kang CM, Han JS, Sunwoo Y. Hydrogen peroxide concentrations in the ambient air of Seoul, Korea. Atmosph Environ. 2002;36(35):5509-16. 
21. Park J, Plese MR, Puskar MA. Evaluation of a Personal Monitor Employing an Electrochemical Sensor for Assessing Exposure to Hydrogen Peroxide in the Workplace. AIHA J. 2003;64:360-7, https://doi.org/10.1080/15428110308984828.

22. Toniolo R, Geatti P, Bontempelli G, Schiavon G. Amperometric monitoring of hydrogen peroxide in workplace atmospheres by electrodes supported on ion-exchange membranes. J Electroanal Chem. 2001;514:123-8, https://doi. org/10.1016/S0022-0728(01)00612-X.

23. Chellmani A, Suresh R. Kinetics and mechanism of oxidation of triphenylphosphine by hydrogen peroxide. React Kinet Catal L. 1988;37:501-5, https://doi.org/10.1007/ BF02062106.

24. Pinkernell U, Effkemann S, Karst U. Simultaneous HPLC Determination of Peroxyacetic Acid and Hydrogen Peroxide. Anal Chem. 1997;69:3623-27, https://doi.org/10.1021/ ac9701750.

25. Augusto F, Koziel J, Pawliszyn J. Design and Validation of Portable SPME Devices for Rapid Field Air Sampling and Diffusion-Based Calibration. Anal Chem. 2001;73:481-6, https://doi.org/10.1021/ac000629k.

26. Koziel J, Jia M, Khaled A, Noah J, Pawliszyn J. Field air analysis with SPME device. Anal Chim Acta. 1999;400:15362, https://doi.org/10.1016/S0003-2670(99)00614-5.

27. Effkemann S, Brødsgaard S, Mortensen P, Linde SA, Karst U. Spectrophotometric and direct-reading methods for the analysis of gas phase peroxyacetic acid. Fresenius J Anal Chem. 2000;36:361-64, https://doi.org/10.1007/s002160050073.

28. Pacenti M, Dugheri S, Boccalon P, Arcangeli G, Dolara P, Cupelli V. Air monitoring and assessment of occupational exposure to peracetic acid in a hospital environment. Ind Health. 2010;48:217-21, https://doi.org/10.2486/indhealth. 48.217 .

29. Hunsaker HA. Methods to infer the compliance status with interval-averaged and with instantaneous occupational exposure limits from the results of longer-duration, integrated air sampling. J Occup Environ Hyg. 2016;13:D1-7, https:// doi.org/10.1080/15459624.2015.1091965.
30. DugheriS, BonariA,Pompilio I,Colpo M,MontaltiM,MucciN, et al. Assessment of occupational exposure to gaseous peracetic acid. Int J Occup Med Environ Health. 2018;31(4):527-35, https://doi.org/10.13075/ijomeh.1896.01166.

31. Dugheri S, Bonari A, Pompilio I, Colpo M, Mucci N, Arcangeli G. An Integrated Air Monitoring Approach for Assessment of Formaldehyde in the Workplace. Saf Health Work 2018;9:479, https://doi.org/10.1016/j.shaw.2018.05.002.

32. Caruso R, Magon A, Dellafiore F, Griffini S, Milani L, Stievano A, et al. Affiliations Italian version of the Assessment of Interprofessional Team Collaboration Scale II (I-AITCS II): a multiphase study of validity and reliability amongst healthcare providers. Med Lav. 2018;109(4):316-24, https://doi. org/10.23749/mdl.v109i4.7101.

33. Leso V, Fontana L, Iavicoli I. The occupational health and safety dimension of Industry 4.0. Med Lav. 2018;110(5):32738, https://doi.org/10.23749/mdl.v110i5.7282.

34. Dini G, Bragazzini NL, Monteucco A, Toletone A, Debarbieri N, Durando P. Big Data in occupational medicine: the convergence of -omics sciences, participatory research and e-health. Med Lav. 2019;110(2):102-14, https://doi.org/ 10.23749/mdl.v110i2.7765.

35. Borak J, Brosseau LM. The past and future of occupational exposure limits. J Occup Environ Hyg. 2015;12(Suppl 1): S1-3, https://doi.org/10.1080/15459624.2015.1091263.

36. Weck M. H2O2-an environmentally acceptable textile bleaching agent Text. Praxis Int. 1991;2:144-7.

37. Kaelin RM, Kapanci Y, Tschopp JM. Diffuse interstitial lung disease associated with hydrogen peroxide inhalation in a dairy worker. Am Rev Respir Dis. 1988;137:1233-5, https://doi.org/10.1164/ajrccm/137.5.1233.

38. Kratz R. [Hermetic sensibility of highly concentrated H2O2. Safety Testing Center]. Thermische sensibilitaet von hochkonzentriertem H2O2. Degussa FCPH-S. Sicherheitstechnisches Prufzentrum; 1999. German.

39. Riihimäki V, Toppila A, Piirila P, Kuosma E, Pfäffli P, Tuomela P. Respiratory health in aseptic packaging with hydrogen peroxide: a report of two cases. J Occup Health. 2002;44:433-8. 
40. Zika RG, Saltzman ES. Interaction of ozone and hydrogen peroxide in water: implications for analysis of $\mathrm{H} 2 \mathrm{O} 2$ in air. Geophys Res Lett. 1982:9(3):231-4, https://doi.org/10.1029/ GL009i003p00231.

41. Jacob P, Tavares TM, Klockow D. Methodology for the determination of gaseous hydrogen peroxide in ambient air. Fresenius J Anal Chem. 1986;325(4):359-64, https://doi.org/ 10.1007/BF00505460.

42. Keuken MP, Schoonebeek CAM, Wensveen-Louter A, Slanina J. Simultaneous sampling of NH3, HNO3, HC1, SO2 and $\mathrm{H} 2 \mathrm{O} 2$ in ambient air by a wet annular denuder system. Atmos Environ (1967). 1988;22(11):2541-8, https://doi.org/ 10.1016/0004-6981(88)90486-6.

43. Bland JM, Altman DG. Measuring agreement in method comparison studies. Stat Methods Med Res. 1999;8:135-60, https://doi.org/10.1177/096228029900800204.

44. Krouwer JS. Why Bland-Altman plots should use X, not $(\mathrm{Y}+\mathrm{X}) / 2$ when $\mathrm{X}$ is a reference method. Stat Med. 2008;27:778-80, https://doi.org/10.1002/sim.3086.
45. Budd JR, Durham AP, Gwise TE, Iriarte B, Kallner A, Linnet K, et al. CLSI Measurement procedure comparison and bias estimation using patient samples. 3rd ed. CLSI guideline EP09c. Wayne: Clinical and Laboratory Standards Institute; 2018.

46. Linnet K, Boyd JC. Selection and analytical evaluation of methods-with statistical techniques. In: Burtis CA, Ashwood ER, Bruns DE, editors. Tietz Textbook of Clinical Chemistry and Molecular Diagnostics. 5th ed. St Louis: Elsevier Saunders; 2012. p. 201-28.

47. Passing H, Bablok W. A new biometrical procedure for testing the equality of measurements from two different analytical methods. Application of linear regression procedures for method comparison studies in Clinical Chemistry, Part I. J Clin Chem Clin Biochem. 1983;21:709-20.

This work is available in Open Access model and licensed under a Creative Commons Attribution-NonCommercial 3.0 Poland License - http://creativecommons.org/ licenses/by-nc/3.0/pl/deed.en. 